POLSK A AKADEMIA NAUK

\title{
INSTYTUT ZOOLOGII
}

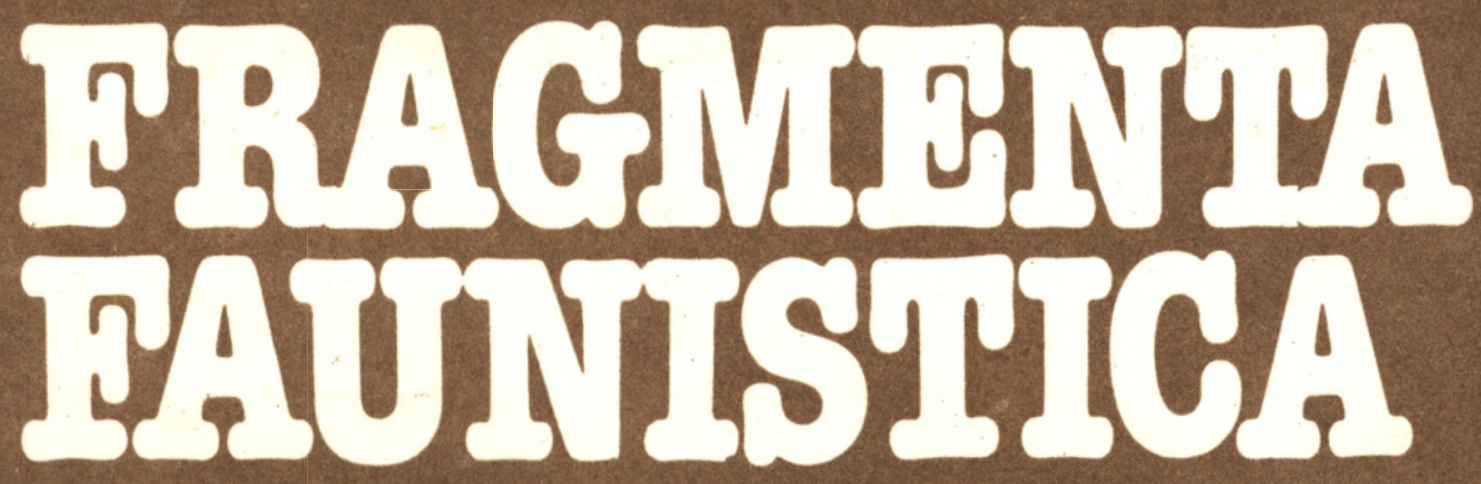

Fauna Gór Świętokrzyskich. IV

TOM 30 NR 1-8

h:

PANSTWOWE WYDAWNICTWO NAUKOWH

WARSZAWA - WROCLAW 
Elżbieta Chudzicka, Henryk Garbarezyk, Andrzej Leśniak, Anna Liana, Eligiusz Nowakowski, Regina Pisarska (redaktor naezelny), Wojciech Staręga, Barbara Zielińska (sekretarz)

\author{
Adres Redakcji \\ Instytut Zoologii Polskiej Akademii Nauk \\ 00-679 Warszawa, ul. Wileza 64 \\ (C) Copyright by Państwowe Wydawnictwo Naukowe \\ Warszawa 1986
}

ISBN 83-01-07005-6

ISSN 0015-9301

Państwowe Wydawnictwo Naukowe - Oddzial Wroclawski

Nakład 570+80 egz. Ark. wyd.10,75; ark. druk. 8,5. Papier druk. sat. kl. III, 80g.

$\mathrm{Nr}$ zam. 3413/85. J-17. Cena $200 \mathrm{zl}$

Wrocławska Drukarnia Naukowa

http://rcin.org.pl 


\section{Fauna \\ Gór Świętokrzyskich}

Część IV 
Prace wykonane w ramach Problemu Międzyresortowego MR II-3. 


\section{TRESĆ - CONTENTS}

Nr 1. A. Piechocki. Rzeki i potoki Okręgu Łysogórskiego jako teren badań hydrobiologieznyeh . . . . . . . . . . . . . . . . . . . . . . .

Nr 2. G. Glapska. Chruściki (Trichoptera) rzek lessowego obrzeża Gór Swiętokrzyskich . . . . . . . . . . . . . . . . . . . . . . . . . . . .

Nr 3. K. Kahl. Skąposzezety (Oligochaeta) rzeki Lubrzanki w Górach Świętokrzyskich ..............................

Nr 4. S. Krajewski. Pluskwiaki różnoskrzydłe (Heteroptera) rzeki Lubrzanki w Górach Świętokrzyskich . . . . . . . . . . . . . . . . . . . . . . . . .

Nr 5. R. Wagner, S. Niesiolowski. Psychodidae (Diptera, Nematocera) found over streams of the Swiętokrzyski National Park and its surroundings . . . . .

Nr 6. S. Niesiolowski. Diptera of the genus Hilara Meigen (Empididae, Brachycera) occurring in the Swiętokrzyskie Mountains in Central Poland . . . . . . . .

$\mathrm{Nr}$ 7. J. Wiedeńska. Sygaczowate (Diptera, Limoniidae) Gór Świętokrzyskich. Cz. I. Limoniidae doliny Lubrzanki . . . . . . . . . . . . . . . . . . . . .

Nr 8. A. Abraszewska-Kowalezyk. Mięczaki (Mollusca) rozlewisk łąkowych w Górach Świętokrzyskich 

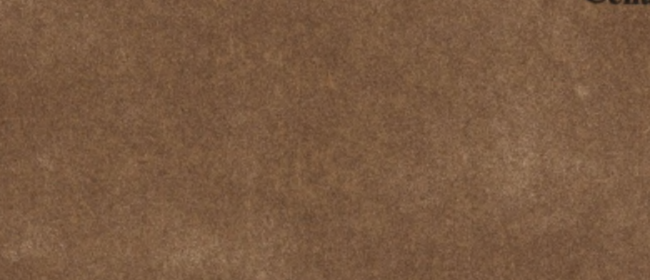

$$
(x+2)
$$
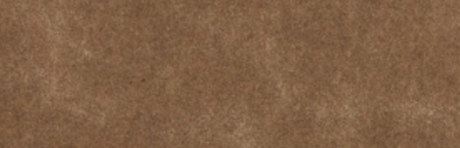